\title{
Expression of selected microRNAs in pancreatic ductal adenocarcinoma: is there a relation to tumor morphology, progression, and patient's outcome?
}

\author{
A. SZABO ${ }^{1}$, R. GURLICH ${ }^{2}$, M. LIBERKO ${ }^{3}$, R. SOUMAROVA 3 , Z. VERNEROVA ${ }^{1}$, V. MANDYS ${ }^{1}$, A. POPOV MP $^{1, *}$ \\ ${ }^{1}$ Department of Pathology, 3rd Faculty of Medicine, Charles University and University Hospital Kralovske Vinohrady, Prague, Czech Republic; \\ ${ }^{2}$ Department of Surgery, 3rd Faculty of Medicine, Charles University and University Hospital Kralovske Vinohrady, Prague, Czech Republic; \\ ${ }^{3}$ Department of Radiotherapy and Oncology, 3rd Faculty of Medicine, Charles University and University Hospital Kralovske Vinohrady, Prague, \\ Czech Republic \\ *Correspondence: alexey.popov@lf3.cuni.cz
}

Received January 23, 2020 / Accepted April 22, 2020

\begin{abstract}
Pancreatic ductal adenocarcinoma (PDAC) remains a disease with extremely poor prognosis and limited effective available treatment. Differential expression of miRNAs isolated from tumor tissue has been proposed as a marker for tumor diagnosis, progression, and prognosis. Nevertheless, the prognostic value of miRNAs expression in PDACs for patient outcome still remains unclear. Expression of 7 selected miRNAs, isolated from FFPE samples of 54 PDAC patients, was quantified using RT-qPCR. The relationship of miRNA expression levels with tumor histology, clinicopathological characteristics, patient overall survival (OS), and progress-free survival (PFS), was subsequently evaluated. Overexpression of miR-21, miR-155, and miR-210 was observed in PDACs (up to 72.62, 232.36, and 181.38-fold, respectively), in comparison with non-neoplastic tissues. On the other hand, miR-96 and miR-217 were significantly downregulated in PDACs (up to one hundred times). No differences were, however, noticed between cancer and normal tissues for the expression levels of miR-148a and miR-196a. On the other hand, expression levels of all 7 miRNAs failed to demonstrate a significant correlation with parameters of tumor progression, such as tumor stage, grade, nodal involvement, perineural, and vascular invasion. The positive correlation of miR-210 levels was, however, observed with patient age $(\rho=0.35)$. Additionally, miR-148a and miR-217 expressions have shown a positive association with tubular tumor growth pattern $(\rho=0.39 ; \rho=0.28)$. The negative correlation of miR-148a values was also demonstrated with dissociative growth pattern and nuclear atypia $(\rho=-0.30$; $\rho=-0.27$ ). Finally, no statistically significant correlation could be demonstrated with the expression levels of all 7 tested miRNAs and PDAC patient survival; neither for OS nor for PFS ( $\mathrm{p}>0.05)$. Our data have confirmed abnormal miRNAs expression in PDACs in comparison with adjacent non-neoplastic tissue. On the other hand, no correlation was discovered between miRNA expression and parameters of tumor progression. We have found a significant association between histologic tumor growth patterns and miRNA expression, making this work the first study, which analyses this aspect of PDAC. Finally, in our group of patients, no relationship of miRNA levels and patient prognosis could be demonstrated. Therefore, further investigation is required to evaluate the predictive and prognostic potential of miRNAs in a clinical setting.
\end{abstract}

Key words: miRNA, pancreatic ductal adenocarcinoma, RT-qPCR (reverse transcription quantitative PCR), overall survival, progression-free survival

Pancreatic ductal adenocarcinoma (PDAC) is the most common primary pancreatic neoplasm, with great potential for locoregional spread (close to $35 \%$ of cases) and, in up to $50 \%$ of patients, with metastatic disease at the time of diagnosis. Furthermore, PDAC is highly resistant to chemoradiotherapy [1-3]. Curative resection is possible only in $15-20 \%$ of the patients, with 5-year overall survival (OS) of $5-7 \%$ [4-8]. Despite dramatic progress in the management of malignancies, the outcome of PDAC patients failed to show significant improvement and by 2030, PDAC is estimated to be the second leading cause of cancer-related death [9]. Therefore, there is an intensive ongoing search for biomarkers permitting tumor detection, characterization of cancer progression, and prediction of patient survival.

MicroRNAs (miRNAs) have emerged as a new class of such biomarkers $[10,11]$. Dysregulation in miRNA expression profiles has been detected in a wide variety of neoplastic diseases [12-14]. They have been theorized to act as oncogenes and tumor suppressors, with aberrant miRNA expression being already presented in neoplastic precursor lesions [15-17]. miRNAs can be isolated from plasma, tissue samples, and excretions while maintaining sample integ- 
rity due to their stability [18-20]. Moreover, miRNAs are preserved after formalin fixation and can be isolated from paraffin-embedded tissue, yielding similar results to fresh material [21].

Several microRNAs across numerous publications have been proposed as predictive factors for disease progression, chemotherapy outcome, and patient survival. Of these markers, miR-21 has received the most of attention, elevated expression levels being regularly suggested as a predictor of poor patient prognosis [22]. Jamieson et al. have also discovered the relationship of miR-21, alongside miR-146a, and miR-628 with tumor grade, stage, and lymph node status [23]. Other miRNAs have shown promise as prognostic markers as well but were analyzed to a more limited degree, sometimes yielding inconsistent results among studies. Kong et al. have proposed elevated miR-196a serum levels as a predictor of poor survival, besides being able to differentiate resectable and unresectable patients [24]. miR-155 has also been linked to advanced tumor stage and poor survival $[25,26]$. Greither et al. have proposed a prognostic panel consisting of miR-155, -203, -210, and -222 , where their elevated expression is a predictor of poor outcome [27]. On the other hand, increased plasma levels of miR-210 were linked to better patient survival [28].

In this study, the expression of 7 miRNAs (miR-21, miR-96, miR-148a, miR-155, miR-196a, miR-210, and miR-217), described to be dysregulated in PDAC, was analyzed. Three of the selected miRNAs, miR-21, miR-155, and miR-217 were described to be differentially expressed in relationship with tumor progression $[23,25,29]$. miR-21, miR-155, miR-196a, and miR-210 were selected, due to having being proposed as prognostic markers $[22,27,30]$. The role of miR-96, as well as miR-148a and miR-217 expression in patient prognosis, has not been analyzed extensively yet. The aim of this work was evaluation of the relationship of miRNA expression levels with tumor morphology, progression, and patients' survival.

\section{Patients and methods}

Patients and tissue specimens. For this study, tissue samples were collected from patients who had undergone pancreatoduodenectomy (Whipple and TraversoLongmire), distal pancreatectomy, or total pancreatectomy for PDAC between 2007 and 2015. Formalin fixed paraffin embedded (FFPE) blocks with tumor and with normal pancreatic tissue, used as a negative control, were retrieved from the archive of the Department of Pathology of the University Hospital Kralovske Vinohrady in Prague. Tumor tissue represented at least two thirds of the volume of the histologic slide. Negative controls of non-neoplastic pancreatic tissue were procured at least $15 \mathrm{~mm}$ away from the tumor. The diagnosis of PDAC was confirmed by two pathologists (A.S., V.M.) according to the WHO Classification of Tumors of the Gastrointestinal Tract, $4^{\text {th }}$ edition. Patient data, including age, gender, tumor grade, and TNM status was collected for analysis. Patients were followed up until January of 2018, with a median follow-up time of 19 months. All patients provided informed written consent for their tissues to be used for scientific research and to publish their case details (resolution 1006/2012). The study was performed according to the Declaration of Helsinki and approved by the Ethics Committee of the Third Faculty of Medicine (Charles University in Prague, Czech Republic).

Morphological analysis of tumors. Microscopic patterns of PDAC were classified into the tubular, cribriform, solidtrabecular, mucinous, clear cell, dissociative, and signet ring; quantified in increments of 5\%, taking into account all the available slides with the tumor. Tumor growth patterns are illustrated in Figure 1. Nuclear atypia was semiquantitatively graded as low, medium, or high. Mitotic count for each tumor was also performed in 10 high power fields (HPF) (Olympus microscope BX43 and objective Olympus Plan $40 \times / 0.65)$.

MicroRNAs isolation and reverse transcription. Three $6 \mu \mathrm{m}$ thick unstained sections from selected FFPE blocks, where the tumor occupied at least two thirds, were procured for RNA extraction, using the miRNeasy FFPE kit (Qiagen), following the manufacturer's instructions. Reverse transcription was carried out as described in our previous work [31].

Table 1. Stem-loop primers for the miRNAs.

\begin{tabular}{ll}
\hline miRNA name: & Stem-loop Primer sequence: \\
\hline miR-39 C. elegans & GTCGTATCCAGTGCAGGGTCCGAGGTATTC- \\
& GCACTGGATACGACTATTAC \\
miR-21 & GTCGTATCCAGTGCAGGGTCCGAGGTATTC- \\
miR-96 & GCACTGGATACGACTCAACA \\
miR-148a & GCACTGGATACGAGACAGGTCCGAGGTATTC- \\
& GTCGTATCCAGTGCAGGGTCCGAGGTATTC- \\
miR-155 & GCACTGGATACGACAGTCGGAG \\
miR-196a & GCACTGGATACGACACCCCTATCACG \\
miR-210 & GTCGTATCCAGTGCAGGGTCCGAGGTATTC- \\
& GCACTGGATACGACCCCAACAACATG \\
miR-217 & GCACTGGATCAGTGCAGGGTCCGAGGTATTC- \\
& GTCGTATCCAGTGCAGGGTCCGAGGTATTC- \\
& GCACTGGATACGACTCCAATCAGTTC \\
\hline
\end{tabular}

Table 2. Real-time qPCR primers.

\begin{tabular}{ll}
\hline Primer name: & Primer sequence: \\
\hline Universal primer & ATCCAGTGCAGGGTCCGAGG \\
miR-39 C. elegans & GCGGCGGAGCTGATTTCGTCTTG \\
miR-21 & GCGGCGGTAGCTTATCAGACTG \\
miR-96 & GCGGCGGTTTGGCACTAGCAC \\
miR-148a & GCGGCGGAAAGTTCTGAGACACTCC \\
miR-155 & GCGGCGGTTAATGCTAATCGTG \\
miR-196a & GCGGCGGTAGGTAGTTTCATGTTG \\
miR-210 & GCGGCGGCTGTGCGTGTGACAG \\
miR-217 & GCGGCGGTACTGCATCAGGAAC \\
\hline
\end{tabular}




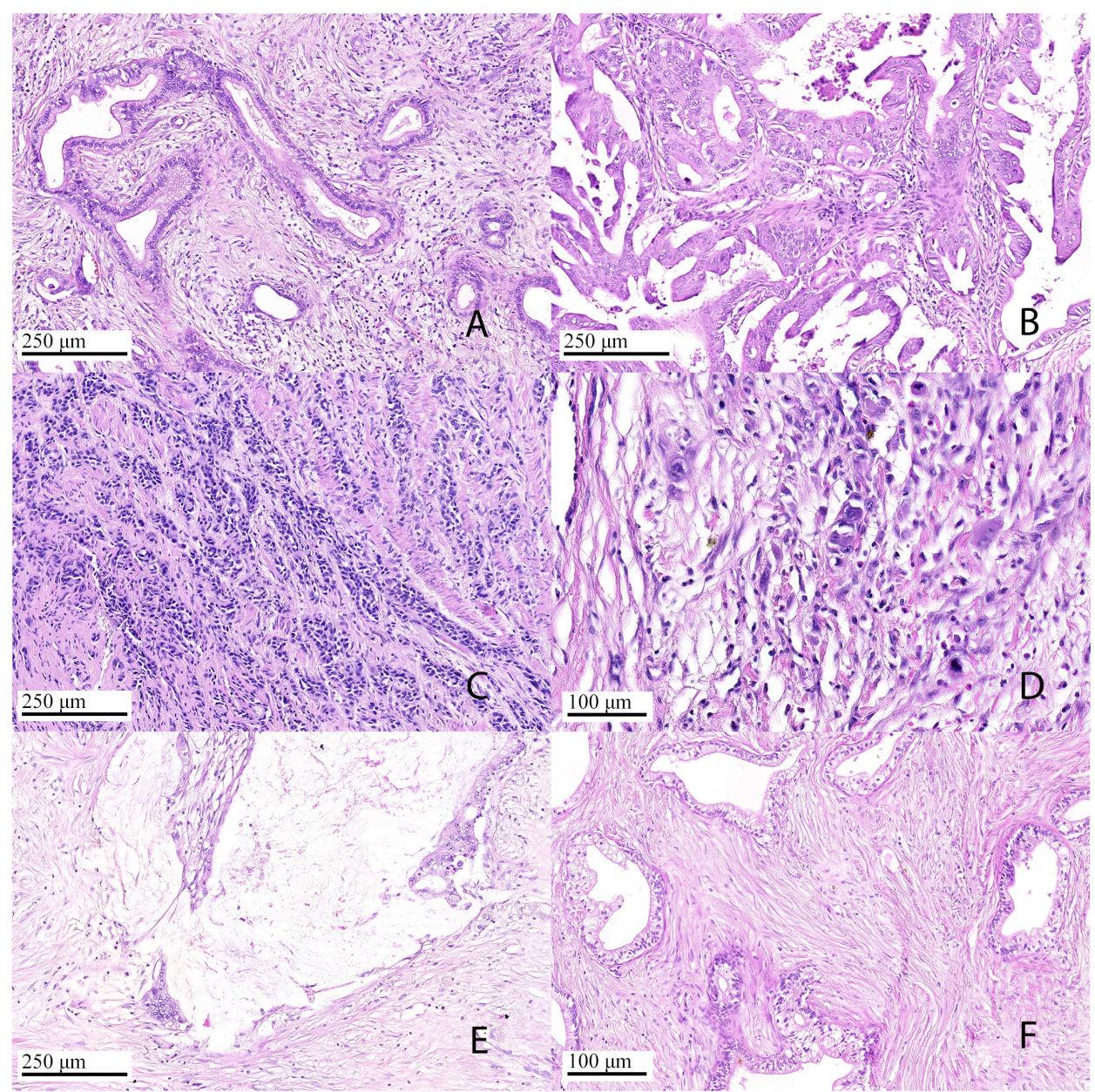

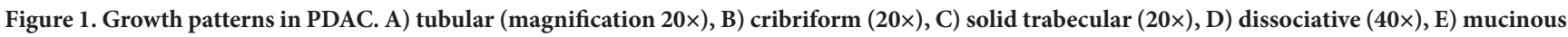
$(20 \times)$, and F) clear cell $(20 \times)$.

The stem-loop primer sequences for the examined pancreatic miRNAs and the internal control, alien spike miRNA (miR-39 from C. elegans) are listed in Table 1. The alien spike was selected for normalization based on its performance in our previous work [31].

Real-time qPCR. cDNA samples were amplified in duplicates, using the Applied Biosystems 7500 Fast real-time PCR system and Hot FirePol EvaGreen qPCR Mix Plus (Solis BioDyne). The reaction mix included $10 \mathrm{pmol}$ of each primer (miRNA specific and the universal; Table 2) and $2 \mu \mathrm{l}$ of cDNA. Amplification of the cDNAs was performed at the following thermal conditions: denaturation at $94^{\circ} \mathrm{C}$ for $15 \mathrm{~min}$, followed by 40 cycles consisting of denaturation at $94^{\circ} \mathrm{C}$ for $15 \mathrm{~s}$, annealing at $62^{\circ} \mathrm{C}$ for $60 \mathrm{~s}$ and DNA synthesis at $72{ }^{\circ} \mathrm{C}$ for $40 \mathrm{~s}$. Reaction product specificity was controlled with their respective melting curves. The $2^{-\Delta \Delta \mathrm{Ct}}$ method was applied to measure the values of miRNA expression of interest [32].

Statistical analysis. All statistical analyses were performed using GenEx 6, S.A.S. release 9.4 (SAS Inc., Cary,
NC, USA), and SPSS 25 (IBM Corporation). The expression of miRNAs in neoplastic and normal tissues was compared by Wilcoxon's paired test. Spearman rank correlation was used to evaluate the correlation between expression levels of different miRNAs. Cox proportional-hazards model was used for analyses of overall and progression-free survival (PFS). Univariate Cox regression analysis was utilized to assess the relationship of miRNA expression and overall survival in the group of patients form the "The Cancer Genome Atlas" (TCGA) database. All tested hypotheses were two-sided. The level of significance was selected as $\alpha=0.05$, therefore $p$-values $<0.05$ were considered as statistically significant.

\section{Results}

Clinicopathological characteristics of PDAC patients. Of 54 patients with PDAC, 27 (50\%) were males and 27 $(50 \%)$ were females, the age of patients ranged from 34 to 83 years, median 63 years (Table 3 ). Four cancers were well- 
differentiated, 27 cancers were moderately differentiated and 23 cancers were poorly differentiated. In one patient, the tumor originated from a mucinous cystic neoplasm (MCN); the analyzed sample was selected to contain only the malignant tumor. The tumor progression was classified in 4 patients pT1, in 7 patients pT2, in 41 patients pT3 and in 2 patients pT4. Lymph node metastases were discovered in 37 specimens. Perineural propagation was present in 47, and lymphovascular invasion in 29 cases. The resection margin was negative (R0) in 40 and positive (R1) in 14 patients (Table 3).

Correlation of tumor histological characteristics. Analysis of the relations of particular histomorphological patterns of PDACs using Spearman's correlation showed negative correlation of tubular tumor pattern (being present in tumors with lower grade) with solid trabecular $(\mathrm{p}<0.001)$ and dissociative $(\mathrm{p}<0.001)$ growth patterns, high nuclear atypia $(p<0.001)$, and mitotic count $(p<0.001)$. Hallmarks of high tumor grade, which are solid trabecular and dissociative growth patterns were, on the other hand, associated with higher degrees of nuclear atypia $(p<0.001)$. High mitotic count in PDAC was also related with nuclear atypia $(\mathrm{p}<0.001)$.

Survival. Data on progression-free survival were available in 42 patients, with a median of 13 months. Overall survival of the entire group ranged between 1-81 months, with a median of 19 months. Seven patients have shown no recurrence of the disease and have survived for 20-81 months, still being alive at the end of the follow-up period (Table 3 ).

Relationship of tumor parameters and patient survival. Evaluation of the prognostic significance of the tumor stage was limited by the number of patients. No difference in prognosis could be demonstrated between grade 2 and grade 3 PDACs $(\mathrm{p}>0.05)$. The small number of grade 1 tumors $(\mathrm{n}=$ 4 ) in our group did not permit us to further characterize the deviation in survival according to this parameter. The positive resection margin was associated with shorter PFS $(\mathrm{p}<0.05)$. Vascular invasion was significantly correlated with the poor patient OS $(\mathrm{p}<0.05)$. No such relationship was apparent in perineural invasion and lymph node status. Microscopic tumor growth patterns, including tubular, cribriform, solid trabecular, and dissociative, were not associated with patient prognosis. The strongest correlation of OS and PFS was with tumor mitotic count $(\mathrm{p}=0.093$ and $\mathrm{p}=0.063)$. We identified a cut-off point of 3 mitoses on $10 \mathrm{HPF} 40 \times$ to distinguish between patients with poor and good prognosis.

Abnormal miRNA expression in pancreatic cancers. We observed significant overexpression of miR-21, miR-155, and miR-210 (up to 72.62-fold, 232.36-fold, and 181.38-fold respectively; $\mathrm{p}<0.01$, Table 4 ) in PDACs in comparison with adjacent normal tissues. On the other hand, miR-96 was significantly downregulated in PDACs $(-1.4$-fold, $\mathrm{p}<0.01)$. Expression of the miR-217 was often inhibited, up to one hundred times and was not detected in 15 PDAC samples (Table 4). However, we did not find any significant differ- ences between cancer and normal tissues for the expression levels of miR-148a and miR-196a ( $p>0.05$, Table 4).

We detected significant positive correlation between expression levels of different miRNAs. High levels of miR-21 correlated with high levels of the miR-155 $(\rho=0.48, p<0.01)$ and miR-210 $(\rho=0.36, p<0.01$, Table 5). Downregulation of miR-96 correlated with miR-196a $(\rho=0.42, p<0.01$, Table 5). Correlation between miR-155 and miR-210 $(\rho=0.30, p<0.05)$ as well as between miR-148a and miR-217 $(\rho=0.27, p=0.048)$ was significant for the $95 \%$ and insignificant for $99 \%$ confidence interval (Table 5).

miRNAs expression and clinicopathological characteristics. Comparison of miRNA expression with clinicopathological characteristics of patients disclosed positive correlation of miR-210 expression with patient age $(\rho=0.35, p<0.01$; Table 6). Expression levels of all 7 miRNAs, failed to demon-

Table 3. Clinicopathological characteristics of 54 PDAC patients.

\begin{tabular}{ll}
\hline Age (Median) & 63 \\
Gender (male/female) & $27 / 27$ \\
Tumor grade (1/2/3) & $4 / 27 / 23$ \\
Tumor stage (pT1/T2/T3/T4) & $4 / 7 / 41 / 2$ \\
Lymph node metastasis (N1/N0) & $37 / 16$ \\
Perineural invasion (yes/no) & $47 / 7$ \\
Lymph vessel invasion (yes/no) & $29 / 25$ \\
Resection margin (R1/R0) & $14 / 40$ \\
PFS length (in months) & $0-81$ \\
median & 13 \\
OS length (in months) & $5-81$ \\
median & 19 \\
\hline
\end{tabular}

Table 4. Average miRNAs fold change values in pancreatic cancers in comparison with normal tissues.

\begin{tabular}{|c|c|c|c|}
\hline \multirow{2}{*}{ miRNAs } & \multicolumn{3}{|c|}{ miRNAs expression fold change } \\
\hline & Min & Max & Mean \pm SD \\
\hline \multirow{2}{*}{$\operatorname{miR}-21$} & \multirow{2}{*}{-16.12} & \multirow{2}{*}{72.62} & $12.01 \pm 14.242$ \\
\hline & & & $\mathrm{p}<0.001$ \\
\hline \multirow{2}{*}{ miR-96 } & \multirow{2}{*}{-18.52} & \multirow{2}{*}{6.22} & $-1.42 \pm 3.981$ \\
\hline & & & $\mathrm{p}<0.001$ \\
\hline \multirow{2}{*}{ miR-148a } & & \multirow{2}{*}{42.3} & $-1.63 \pm 10.762$ \\
\hline & -55.56 & & $\mathrm{p}=0.08$ \\
\hline \multirow{2}{*}{ miR-155 } & \multirow{2}{*}{-13.16} & \multirow{2}{*}{232.36} & $22.91 \pm 38.526$ \\
\hline & & & $\mathrm{p}<0.001$ \\
\hline \multirow{2}{*}{ miR-196a } & \multirow{2}{*}{-15.38} & \multirow{2}{*}{25.9} & $0.913 \pm 5.574$ \\
\hline & & & $\mathrm{p}=0.91$ \\
\hline \multirow{2}{*}{ miR-210 } & \multirow{2}{*}{-4.0} & \multirow{2}{*}{181.38} & $15.68 \pm 28.869$ \\
\hline & & & $\mathrm{p}<0.001$ \\
\hline \multirow{2}{*}{ miR-217 } & \multirow{2}{*}{$-100\left(0^{*}\right)$} & \multirow{2}{*}{15.87} & $-7.45 \pm 16.537$ \\
\hline & & & $\mathrm{p}<0.001$ \\
\hline
\end{tabular}

Total number of patients 54. Data are presented as means \pm standard deviation (SD). Negative fold change values indicate downregulation of the miRNAs in cancer samples. ${ }^{*}$ Expression of miR-217 was not detected in 15 PDACs. $\mathrm{p}<0.05$ is considered as statistically significant; $\mathrm{p}$-values of the Wilcoxon's test for the significant differences are shown in bold 
strate a significant correlation with other parameters, such as tumor stage, grade, nodal involvement, perineural and vascular invasion (Table 6).

miRNA expression and microscopic tumor growth patterns. Evaluation of the relationship between miRNA expression and microscopic tumor patterns, using Spearman's correlation discovered statistically significant association of miR-148a and miR-217 expression and tubular tumor growth pattern, characteristic for cancers of lower grade $(\rho=0.39, p<0.01 ; \rho=0.28, p<0.05$; Table 7$)$. miR-148a values have shown a negative correlation with nuclear atypia $(\rho=-0.30, p<0.05$; Table 7$)$ and dissociative growth pattern $(\rho=-0.28, p<0.05$; Table 7$)$. Additionally, miR-155 level had positive correlation with high tumor mitotic count $(\rho=0.27$, $\mathrm{p}<0.05$; Table 7).
miRNA expression and patient's survival. Analysis of a prognostic role of the expression of tested miRNAs in PDAC did not discover any significant evidence for OS ( $p>0.05$, Table 8). Correlation between miRNA levels and the duration of PFS was also statistically insignificant for all seven selected miRNAs ( $\mathrm{p}>0.05$, Table 9).

In silico survival analysis of survival of PDAC patients from the TCGA database. "The Cancer Genome Atlas" (TCGA) database represents miRnome of 178 pancreatic carcinomas analyzed by Illumina seq (https://gdc.cancer. gov, oncolnc.org), alongside with the detailed clinical patient data. After review of the TCGA cohort, we excluded cases of neuroendocrine carcinomas and adenocarcinomas other than conventional PDAC; the size of the analyzed TCGA cohort was thus reduced to 160 patients. The relationship

Table 5. Correlation of expression levels between different miRNAs.

\begin{tabular}{|c|c|c|c|c|c|c|c|}
\hline & miR-21 & miR-96 & miR-148a & miR-155 & miR-196a & miR-210 & miR-217 \\
\hline \multirow{2}{*}{ miR-21 } & 1 & 0.11 & 0.12 & 0.48 & 0.18 & 0.36 & -0.04 \\
\hline & $\mathrm{p}=0$ & $\mathrm{p}=0.39$ & $\mathrm{p}=0.41$ & $\mathrm{p}<0.001$ & $\mathrm{p}=0.21$ & $p<0.01$ & $\mathrm{p}=0.77$ \\
\hline \multirow{2}{*}{ miR-96 } & 0.11 & 1 & 0.11 & 0.12 & 0.43 & -0.004 & 0.02 \\
\hline & $\mathrm{p}=0.39$ & $\mathrm{p}=0$ & $\mathrm{p}=0.42$ & $\mathrm{p}=0.40$ & $\mathrm{p}<0.01$ & $\mathrm{p}=0.97$ & $\mathrm{p}=0.92$ \\
\hline \multirow{2}{*}{ miR-148a } & 0.12 & 0.11 & 1 & 0.09 & -0.16 & 0.08 & 0.28 \\
\hline & $\mathrm{p}=0.41$ & $\mathrm{p}=0.42$ & $\mathrm{p}=0$ & $\mathrm{p}=0.54$ & $\mathrm{p}=0.26$ & $\mathrm{p}=0.55$ & $\mathrm{p}=0.048$ \\
\hline \multirow{2}{*}{ miR-155 } & 0.48 & 0.12 & 0.09 & 1 & -0.06 & 0.30 & -0.11 \\
\hline & $\mathrm{p}<0.001$ & $\mathrm{p}=0.40$ & $\mathrm{p}=0.54$ & $\mathrm{p}=0$ & $\mathrm{p}=0.66$ & $\mathrm{p}=0.03$ & $\mathrm{p}=0.43$ \\
\hline \multirow{2}{*}{ miR-196a } & 0.18 & 0.43 & -0.16 & -0.06 & 1 & 0.05 & 0.04 \\
\hline & $\mathrm{p}=0.21$ & $p<0.01$ & $\mathrm{p}=0.26$ & $\mathrm{p}=0$ & $\mathrm{p}=0$ & $\mathrm{p}=0.74$ & $\mathrm{p}=0.77$ \\
\hline \multirow{2}{*}{ miR-210 } & 0.36 & -0.004 & 0.08 & 0.30 & 0.05 & 1 & -0.06 \\
\hline & $\mathrm{p}<0.01$ & $\mathrm{p}=0.97$ & $\mathrm{p}=0.55$ & $p=0.03$ & $\mathrm{p}=0.74$ & $\mathrm{p}=0$ & $\mathrm{p}=0.69$ \\
\hline \multirow{2}{*}{ miR-217 } & -0.04 & 0.02 & 0.28 & -0.11 & 0.04 & -0.06 & 1 \\
\hline & $\mathrm{p}=0.77$ & $\mathrm{p}=0.92$ & $\mathrm{p}=\mathbf{0 . 0 4 8}$ & $p=0.43$ & $\mathrm{p}=0.77$ & $p=0.69$ & $\mathrm{p}=0$ \\
\hline
\end{tabular}

Values of the Spearman rank correlation $(\rho)$ for the significant differences are shown in bold. $\mathrm{p}<0.05$ is considered as statistically significant (shown in bold)

Table 6. Correlation of clinicopathological characteristics with miRNAs expression levels.

\begin{tabular}{|c|c|c|c|c|c|c|c|}
\hline \multirow[b]{2}{*}{ miRNA } & \multicolumn{7}{|c|}{ Patient parameters } \\
\hline & Age & Grade & Tumor & $\begin{array}{l}\text { Lymph node } \\
\text { metastasis }\end{array}$ & $\begin{array}{c}\text { Perineural } \\
\text { invasion }\end{array}$ & $\begin{array}{l}\text { Vascular } \\
\text { invasion }\end{array}$ & $\begin{array}{c}\text { Resection } \\
\text { margin }\end{array}$ \\
\hline \multirow{2}{*}{ miR-21 } & 0.22 & 0.14 & 0.08 & -0.06 & 0.02 & 0.01 & -0.03 \\
\hline & $\mathrm{p}=0.12$ & $\mathrm{p}=0.33$ & $\mathrm{p}=0.55$ & $\mathrm{p}=0.63$ & $\mathrm{p}=0.85$ & $\mathrm{p}=0.92$ & $\mathrm{p}=0.78$ \\
\hline \multirow{2}{*}{ miR-96 } & 0.03 & 0.003 & 0.14 & 0.22 & 0.07 & -0.05 & 0.05 \\
\hline & $\mathrm{p}=0.80$ & $\mathrm{p}=0.98$ & $\mathrm{p}=0.31$ & $\mathrm{p}=0.11$ & $\mathrm{p}=0.62$ & $\mathrm{p}=0.70$ & $\mathrm{p}=0.71$ \\
\hline \multirow{2}{*}{ miR-148a } & -0.09 & -0.15 & -0.006 & 0.12 & 0.05 & -0.09 & 0.15 \\
\hline & $\mathrm{p}=0.48$ & $\mathrm{p}=0.28$ & $\mathrm{p}=0.96$ & $\mathrm{p}=0.37$ & $\mathrm{p}=0.69$ & $\mathrm{p}=0.52$ & $\mathrm{p}=0.25$ \\
\hline \multirow{2}{*}{ miR-155 } & 0.19 & 0.02 & 0.14 & 0.0243 & 0.16 & -0.006 & -0.09 \\
\hline & $\mathrm{p}=0.18$ & $\mathrm{p}=0.85$ & $\mathrm{p}=0.31$ & $\mathrm{p}=0.86$ & $\mathrm{p}=0.24$ & $\mathrm{p}=0.96$ & $\mathrm{p}=0.49$ \\
\hline \multirow{2}{*}{ miR-196a } & 0.14 & 0.05 & 0.15 & 0.16 & -0.08 & 0.02 & 0.19 \\
\hline & $\mathrm{p}=0.31$ & $\mathrm{p}=0.72$ & $\mathrm{p}=0.29$ & $\mathrm{p}=0.26$ & $\mathrm{p}=0.53$ & $\mathrm{p}=0.89$ & $\mathrm{p}=0.14$ \\
\hline \multirow{2}{*}{$\operatorname{miR}-210$} & 0.35 & 0.03 & 0.03 & 0.03 & 0.09 & -0.01 & 0.02 \\
\hline & $\mathrm{p}<0.01$ & $\mathrm{p}=0.82$ & $\mathrm{p}=0.80$ & $\mathrm{p}=0.81$ & $\mathrm{p}=0.53$ & $\mathrm{p}=0.89$ & $\mathrm{p}=0.83$ \\
\hline \multirow{2}{*}{ miR-217 } & -0.24 & -0.06 & 0.15 & 0.01 & 0.04 & -0.21 & 0.09 \\
\hline & $\mathrm{p}=0.07$ & $\mathrm{p}=0.66$ & $\mathrm{p}=0.26$ & $\mathrm{p}=0.91$ & $\mathrm{p}=0.74$ & $\mathrm{p}=0.13$ & $\mathrm{p}=0.48$ \\
\hline
\end{tabular}

Values of the Spearman rank correlation $(\rho)$ were used to assess the relationship of morphological tumor parameters with miRNAs expression. $p<0.05$ is considered as statistically significant (shown in bold) 
of copy numbers of selected miRNAs in tumors and patient survival was evaluated with Cox regression analysis, but none of the selected miRNAs were related to shorter patient OS (Supplementary Table S1, $\mathrm{p}<0.05$ ).

\section{Discussion}

MicroRNAs are overexpressed or downregulated in pancreatic cancer. For our analysis, we have selected miRNAs frequently described to be deregulated in PDACs
$[30,33,34]$. Zhang et al. have demonstrated relative expression values of miRNAs spanning 6-logs (from $0.01-10,000$ ) among individual cases [35].

Expression levels of miR-21 are increased in PDAC and vary greatly in individual studies $[30,33,36,37]$. For example, Bloomston et al. measured with microarray a median 2.2-fold increase in FFPE tumor samples [30], and Zhang et al. detected an upregulated expression of miR-21 up to 6888 -fold in several tumors using RT-qPCR arrays [35]. In our study, a mean 12.01-fold increase of miR-21 was

Table 7. Correlation of microscopic tumor growth patterns, nuclear atypia and mitotic activity with miRNAs expression levels.

\begin{tabular}{|c|c|c|c|c|c|c|c|}
\hline \multirow{2}{*}{ Tumor parameters } & \multicolumn{7}{|c|}{ miRNAs } \\
\hline & miR-21 & miR-96 & miR-148a & miR-155 & miR-196a & $\operatorname{miR}-210$ & $\operatorname{miR}-217$ \\
\hline \multirow{2}{*}{ Tubular pattern } & -0.06 & 0.20 & 0.39 & -0.18 & 0.07 & -0.17 & 0.28 \\
\hline & $\mathrm{p}=0.64$ & $\mathrm{p}=0.14$ & $\mathrm{p}<0.01$ & $\mathrm{p}=0.18$ & $\mathrm{p}=0.56$ & $\mathrm{p}=0.21$ & $\mathrm{p}=0.03$ \\
\hline \multirow{2}{*}{ Cribriform pattern } & -0.003 & 0.049 & 0.010 & 0.06 & -0.07 & 0.16 & -0.07 \\
\hline & $\mathrm{p}=0.98$ & $\mathrm{p}=0.72$ & $\mathrm{p}=0.93$ & $\mathrm{p}=0.63$ & $\mathrm{p}=0.60$ & $\mathrm{p}=0.23$ & $\mathrm{p}=0.60$ \\
\hline \multirow{2}{*}{ Solid trabecular } & 0.027 & -0.09 & -0.21 & 0.15 & -0.06 & -0.01 & -0.10 \\
\hline & $\mathrm{p}=0.84$ & $\mathrm{p}=0.49$ & $\mathrm{p}=0.12$ & $\mathrm{p}=0.26$ & $\mathrm{p}=0.65$ & $\mathrm{p}=0.92$ & $\mathrm{p}=0.44$ \\
\hline \multirow{2}{*}{ Dissociative pattern } & -0.04 & -0.08 & -0.28 & 0.03 & -0.05 & 0.01 & -0.11 \\
\hline & $\mathrm{p}=0.74$ & $\mathrm{p}=0.55$ & $p=0.033$ & $\mathrm{p}=0.77$ & $\mathrm{p}=0.67$ & $\mathrm{p}=0.93$ & $\mathrm{p}=0.41$ \\
\hline \multirow{2}{*}{ Clear cell pattern } & 0.158 & 0.051 & -0.005 & 0.17 & 0.09 & 0.19 & -0.15 \\
\hline & $\mathrm{p}=0.25$ & $\mathrm{p}=0.70$ & $\mathrm{p}=0.9$ & $\mathrm{p}=0.21$ & $\mathrm{p}=0.47$ & $\mathrm{p}=0.14$ & $\mathrm{p}=0.27$ \\
\hline \multirow{2}{*}{ Nuclear atypia } & 0.09 & -0.038 & -0.30 & 0.11 & -0.05 & 0.04 & -0.01 \\
\hline & $\mathrm{p}=0.50$ & $\mathrm{p}=0.78$ & $p=0.02$ & $\mathrm{p}=0.40$ & $\mathrm{p}=0.71$ & $\mathrm{p}=0.75$ & $\mathrm{p}=0.89$ \\
\hline \multirow{2}{*}{ Mitotic activity } & 0.18 & -0.16 & -0.10 & 0.27 & -0.01 & 0.08 & -0.24 \\
\hline & $\mathrm{p}=0.16$ & $\mathrm{p}=0.22$ & $\mathrm{p}=0.45$ & $p=0.046$ & $\mathrm{p}=0.89$ & $\mathrm{p}=0.54$ & $\mathrm{p}=0.07$ \\
\hline
\end{tabular}

Values of the Spearman rank correlation $(\rho)$ were used to assess the relationship of morphological tumor parameters with miRNAs expression. $p<0.05$ is considered as statistically significant (shown in bold)

Table 8. Overall survival and miRNAs expression levels in PDAC patients.

\begin{tabular}{|c|c|c|c|c|c|c|c|}
\hline miRNA & $\begin{array}{l}\text { Parameter } \\
\text { Estimate }\end{array}$ & $\begin{array}{c}\text { Standard } \\
\text { Error }\end{array}$ & Chi-Square & p-value & $\begin{array}{c}\text { Hazard } \\
\text { Ratio }\end{array}$ & \multicolumn{2}{|c|}{$\begin{array}{l}\text { 95\% Hazard Ratio } \\
\text { Confidence Limits }\end{array}$} \\
\hline miR-21 & 0.004 & 0.01 & 0.156 & 0.69 & 1.004 & 0.984 & 1.025 \\
\hline miR-96 & 0.023 & 0.143 & 0.026 & 0.87 & 1.023 & 0.772 & 1.356 \\
\hline miR-148a & 0.003 & 0.022 & 0.023 & 0.87 & 1.003 & 0.961 & 1.048 \\
\hline miR-155 & 0.002 & 0.004 & 0.556 & 0.45 & 1.003 & 0.995 & 1.011 \\
\hline miR-196a & -0.017 & 0.045 & 0.147 & 0.70 & 0.983 & 0.899 & 1.074 \\
\hline miR-210 & 0.004 & 0.005 & 0.699 & 0.40 & 1.004 & 0.994 & 1.014 \\
\hline $\operatorname{miR}-217$ & 0.07 & 0.08 & 0.776 & 0.37 & 1.073 & 0.917 & 1.255 \\
\hline
\end{tabular}

Cox proportional-hazards model was utilized to estimate prognostic functions of miRNAs. $p<0.05$ is considered as statistically significant.

Table 9. Progression-free survival and miRNAs expression levels in PDAC patients.

\begin{tabular}{|c|c|c|c|c|c|c|c|}
\hline miRNA & $\begin{array}{c}\text { Parameter } \\
\text { Estimate }\end{array}$ & $\begin{array}{c}\text { Standard } \\
\text { Error }\end{array}$ & Chi-Square & p-value & $\begin{array}{c}\text { Hazard } \\
\text { Ratio }\end{array}$ & \multicolumn{2}{|c|}{$\begin{array}{l}\text { 95\% Hazard Ratio } \\
\text { Confidence Limits }\end{array}$} \\
\hline miR-21 & 0.007 & 0.009 & 0.502 & 0.47 & 1.007 & 0.988 & 1.027 \\
\hline miR-96 & 0.014 & 0.131 & 0.011 & 0.91 & 1.014 & 0.783 & 1.313 \\
\hline miR-148a & 0.046 & 0.024 & 3.605 & 0.06 & 1.047 & 0.999 & 1.099 \\
\hline miR-155 & 0.003 & 0.003 & 0.991 & 0.31 & 1.004 & 0.997 & 1.011 \\
\hline miR-196a & -0.029 & 0.043 & 0.440 & 0.50 & 0.971 & 0.892 & 1.058 \\
\hline miR-210 & 0.005 & 0.004 & 1.527 & 0.21 & 1.006 & 0.997 & 1.015 \\
\hline miR-217 & 0.047 & 0.076 & 0.387 & 0.53 & 1.049 & 0.903 & 1.218 \\
\hline
\end{tabular}

Cox proportional hazards model was used to estimate prognostic functions of miRNAs. $\mathrm{p}<0.05$ is considered as statistically significant. 
observed and a maximum 72 -fold elevation was present in tumors (Table 4).

The data about miR-96 expression in PDAC are controversial. This miRNA has been shown to be downregulated in several studies performed on FFPE tumor samples utilizing microarrays and RT-qPCR [19, 33, 38-40]. On the other hand, Bloomston et al. measured an average 1.77-fold increase, when determining miR-96 levels in PDACs [30]. Kent et al. also demonstrated 2.7-fold upregulation of miR-96 in pancreatic cancer cell lines using custom microarrays [38]. We found that miR-96 expression was significantly downregulated in cancers in comparison with normal tissues (up to -18 -fold, mean was -1.42 -fold, $\mathrm{p}<0.01$, Table 4 ).

A decrease of miR-148a levels has been consistently identified in PDAC tissue samples, across several studies analyzing FFPE tumor tissues with microarrays and RT-qPCR [19, 30, 41]. In contrast with the cited literature, we found slightly decreased miR-148a mean level in tumors (-1.63-fold), but insignificantly in comparison with normal tissues ( $>0.05$, Table 4). However, this miRNA was inhibited, up to -55-fold, in several PDACs (Table 4).

Overexpression of miR-155 in paraffin-embedded PDAC samples and pancreatic cancer cell lines, measured by microarrays and RT-qPCR, ranged from 1.8 to 2.9 -fold in different studies [35, 42, 43]. Zhang et al. reported up to a 52 -fold increase in individual cases [35]. In our group of samples, a mean 22.9-fold increase was present ( $p>0.05$, Table 4).

Abnormalities in miR-196a expression have been described in pancreatic cancer and in other malignancies as well $[34,35,44,45]$. Wang et al. detected with RT-qPCR 16.05-fold increase in plasma samples of patients with PDAC [34]. Additionally, Xu et al. discovered with RT-qPCR a significant increase of miR-196a in plasma exosomes of PDAC patients in comparison with healthy controls [46]. In our group of PDAC patients, we determined a great variation of miR-196a expression, from -15-fold up to 25.9 -fold in different tumors (Table 4). On the other hand, we did not find significant differences in miR-196a expression between cancer and normal tissues (mean was 0.913 -fold, $\mathrm{p}>0.05$; Table 4).

Elevation in miR-210 levels have been consistently described across several studies performed on frozen and FFPE tumor tissues with microarrays and RT-qPCR [19, 27]. Greither et al. detected up to a 39.9-fold increase in snap-frozen surgical resection specimens [27]. Wang et al. reported about a 2-28-fold elevation in miR-210 plasma levels in PDAC patients [34]. In our study, we observed up to a 181-fold increase of miR-210 expression in PDACs in comparison with normal tissues (mean 15.68 -fold, $\mathrm{p}<0.01$; Table 4).

Downregulation of miR-217 is a frequently described phenomenon in PDACs. Greither et al. determined only a mean a -2-fold decrease of miR-217 expression in snapfrozen tumor samples [27]. In FFPE tumor tissues, Ma et al. demonstrated -3.91-fold decrease [47], Szafranska et al. have shown downregulation up to -10 -fold as well [19]. Hong et al. found significant (up to -62.5 -fold) downregulation of miR-217 expression of in fine needle aspirates from PDACs [33]. In our samples, miR-217 expression was significantly downregulated, with up to-100-fold decrease. Additionally, this miRNA was not detected in 15 PDACs $(\mathrm{p}<0.01$, Table 4$)$.

Besides identifying abnormalities in the expression of single miRNAs, we have also discovered a positive correlation between high expression levels of the three oncomiRNAs: miR-21, miR-155a, and miR-210 (Table 5). Acting together, these miRNAs may promote cancer development and progression [48-51]. Moreover, a positive correlation was detected for the downregulation of tumor suppressing miRNAs miR-148a and miR-217 (Table 5). Both of them inhibit cell proliferation [52, 53], therefore it may be necessary to deactivate them in tumors for successful cancerogenesis. Additionally, a positive correlation was detected for the downregulation of miR-96 and upregulation of miR-196a (Table 5). miR-96 is an inhibitor of KRAS, limiting tumor cells proliferation [39, 40,54], but miR-196a is oncomiR and it acts quite opposite, preventing apoptosis [55], promoting cell proliferation, and migration [48]. Accordingly, the downregulation of miR-96 and upregulation of miR-196a look like a necessary condition for tumor survival and development.

Thus, we observed that selected miRNAs were abnormally up- or downregulated in pancreatic cancers. Five of seven selected miRNAs demonstrated significant differences in expression levels in tumors in comparison with adjacent normal tissues (Table 4). Therefore, differential miRNAs expression may be a very sensitive tool for pancreatic cancer diagnostics.

Correlation of clinicopathological features of tumors with microRNA expression. In surgical resection specimens, the relationship of abnormal miRNA expression with tumor morphology and progression has been investigated less frequently, compared with miRNA diagnostic and prognostic utility. Additionally, the conclusions are inconsistent in different publications. Jamieson et al. have demonstrated elevated expression of miR-21, miR-146a, and decreased expression of miR-628 to be linked to tumor grade, stage, and lymph node status in FFPE tumor samples investigated with RT-qPCR [23]. Frampton et al. [56] and Giovanetti et al. [57], on the other hand, found in formalin fixed PDAC tissue samples statistically significant association only between elevated miR-21 levels and tumor grade, but not with other clinicopathological parameters. Dillhoff et al. couldn't identify with in situ hybridization in FFPE tumor samples any correlation of miR-21 expression with tumor size, differentiation, nodal status, or tumor stage [58]. Deng et al. demonstrated in snap-frozen and FFPE samples of a group of $54 \mathrm{PDAC}$ patients positive correlation of downregulated miR-217 with progressed tumor stage, lymphatic invasion, vascular infiltration, and distant metastasis [29]. Schultz et al., in microdissected FFPE tumor 
samples in a group of 170 PDAC patients, could not identify a reliable miRNA profile to categorize patients according to tumor stage and lymph node status [59].In our cases, we haven't detected a significant correlation of miRNA expression with tumor progression, grade, perineural, vascular invasion, and lymph node status. A positive association was, however, discovered between patient age and miR-210 levels (Table 6). This finding could be in part related to the proposed role of miR-210 in cellular senescence [60]. Further investigation is, therefore warranted to analyze the potential of miRNA signatures in predicting the extent of tumor progression.

Prognostic role of miRNAs expression profiles for PDAC patient's overall and progression-free survival. The only clinically available biomarker capable of assessing the prognosis of PDAC patients is CA19-9, yet its utility is limited by non-specific positivity and false negativity in multiple neoplastic and non-neoplastic diseases [61]. There is increasing evidence that miRNA expression profiles could have the potential to provide tumor-specific prognostic information. Several recent works have reported associations between microRNA expression and overall survival in PDAC patients $[22,57,62,63]$.

Among the dysregulated miRNAs in PDAC, miR-21 has been the most widely studied potential prognostic factor. This oncomiRNA has also been proposed as a marker for patient survival in a large number of other malignancies [64]. Several meta-analyses, assessing more than 20 articles, published from 2007 to 2016, including more than 2000 PDAC cases [22, 62-65], have postulated that high miR-21 expression, detected with microarrays and RT-qPCR in tumor tissue samples procured from surgical specimens, is consistently linked to the poor OS and PFS. Similarly, Karasek et al. described the association of poor patient OS and elevated plasma levels of miR-21 detected with RT-qPCR [66]. The literature is, however, not in total agreement regarding the prognostic role of miR-21. Schultz et al. and Calatayud et al. did not find any significant correlation between miR-21 expression, measured with RT-qPCR arrays on FFPE material, and OS in their groups of 165 and 277 PDAC patients [59, 67]. Worse PFS was observed by Khan et al. in patients with the inoperable PDAC with elevated plasma miR-21 detected with digital droplet PCR, but no association of circulating miR-21 levels with OS was detected [68]. Moreover, there is disagreement in the literature over the significance of miR-21 overexpression in the cancer cells or in tumor-associated fibroblasts for patient survival. Donahue et al. described worse OS in patients receiving 5 -fluorouracil chemotherapy with elevated miR-21 expression in cancer-associated fibroblasts detected with in situ hybridization, but not in patients treated with gemcitabine [69]. Kadera et al. identified through in situ hybridization that only elevated miR-21 expression in tumor-associated fibroblasts was linked with poor prognosis and lymph node metastases. On the other hand, miR-21 expression in tumor cells had no effect on survival [70]. Giovanetti et al. detected, however, significantly higher mir-21 levels in microdissected tumor cells, correlating with shorter OS [57].

The role of miR-96 expression levels in patient prognosis has not been analyzed extensively. Only one group demonstrated that downregulated expression of miR-96-5p in FFPE tumor samples measured with RT-qPCR was associated with a decreased overall survival in patients with PDAC [71].

The value of miR-148a as a prognostic marker for PDAC has also been assessed to a limited degree, with controversial conclusions. Schultz et al. identified in FFPE PDAC samples, utilizing RT-qPCR arrays, low miR-148a expression as a predictor of short OS [59]. On the other hand, in FFPE samples from a group of 78 PDAC patients, miR-148 expression levels, quantified with RT-qPCR, were not statistically significant with regards to overall survival [47].

Overexpression of miRNAs miR-155, miR-196a, and miR-210 detected in microarrays and with RT-qPCR performed on frozen and FPPE tumor samples has been observed in pancreatic cancer patients who had a poor overall survival rate $[27,30]$. These findings were confirmed with RT-qPCR by Papaconstantinou et al. and Ma et al. for miR-155 in operatively collected FFPE tumor samples [25, 47]; as well as by Greither et al. for miR-155 and miR-210 in microdissected snap-frozen tumor samples [27]. Mikamori et al. showed that both OS and DFS were significantly shorter in the high miR-155 expression group of microdissected FFPE pancreatic cancer samples [26]. Bloomston et al. have linked high miR-196a in FFPE samples from PDAC, measured with microarrays, with shorter OS [30]. Kong et al. also reported the correlation of elevated miR-196a measured with RT-qPCR in blood sera of PDAC patients with poor survival and advanced disease stage [24]. Yu et al. analyzed plasma levels of miR-196a and miR-210 with RT-qPCR in a cohort of 31 PDAC patients. High miR-196a expression was associated with poor OS, whereas high miR-210 expression was significantly associated with improved survival [28].

The effect of miR-217 expression levels on patient prognosis has been evaluated only by Ma et al. and Vychytilova et al., investigating FFPE tumor samples utilizing RT-qPCR. In these studies, no association of miR-217 expression with OS and PFS was described [47, 72].

In our study, we could not confirm any significant prognostic value of the seven selected miRNAs, neither for OS nor for PFS (Table 8 and 9).

Several studies have examined in silico the RNA sequencing data of pancreatic cancers from the TCGA database, in order to select miRNAs predicting survival length [73-76]. These publications are also not in agreement about the panels of predictive miRNAs for patient OS, which varied significantly in composition (Supplementary Table S2). The miR-21 was determined as significant for patient prognosis in only one of the studies [73]. miR-196a expression was identified as significant for predicting survival in univariate Cox regression analysis in one study but this miRNA was insignificant 
for OS in the multivariate analysis in a combination with another miRNAs [75]. We also analyzed the cohort of 160 PDAC patients from this database [77] but none of the selected miRNAs were related to shorter patient OS (Supplementary Table S1). Discrepancies in selected prognostic miRNAs may be due to differences in study design and statistical data analysis.

The data about the prognostic role of miRNAs expression in PDACs are insufficient and debatable. The number of performed studies is low; as such bias introduced by the composition and ethnicity of the patient cohort may be regarded as a significant source of variability $[65,78]$. The choice of different PDAC samples types, including frozen and FFPE tumor tissues from surgical resection specimens, plasma, or blood serum, each requiring different technical approaches during measurement of miRNA expression, can potentially decrease the comparability of results across studies [79-81]. miRNA yields can also be influenced by the length of storage in fixative agents and by the choice of isolation methods $[79,82]$. In retrospective studies, the storage time of archived FFPE samples may also influence the results due to a gradual decrease in global miRNA yield and selective degradation of individual miRNAs $[79,83]$. The utilization of microdissection in tissue samples could alter the results by excluding miRNAs from tumor-associated fibroblasts [57]. The different analytical methods utilized for quantification of miRNA expression may be an additional source of variability. The comparison of 12 commercially available platforms based on RT-qPCR, microarrays, and RNA seq demonstrated significant differences in the profile of detected miRNAs [84]. The choice of normalization can also significantly alter the detected values of miRNA expression in RT-qPCR [31].

In conclusion, we could not confirm the predictive function of our selected miRNAs, miR-21, miR-96, miR-148a, miR-155, miR-196a, miR-210, and miR-217 for OS and PFS in PDAC patients. The values of miRNA expression showed, however, significant variability among individual studies. Levels of detected miRNAs can be influenced by several factors, including manipulation with samples, choice of miRNA isolation protocols, detection methods, and normalization. These factors limit the comparability of miRNA expression results across the literature. Thus, further largescale studies under standardized sample procurement and analysis protocols are needed to validate, whether miRNAs could serve as prognostic biomarkers for PDAC in the clinical setting.

Supplementary information is available in the online version of the paper.

Acknowledgments: We sincerely thank Dr. Ladislav Pecen for his kindly help with statistical analysis and Dr. Josef Dvorak for kindly providing us with follow-up data. This work was supported by the Charles University research program PROGRES Q 28 (Oncology).

\section{References}

[1] SIEGEL R, NAISHADHAM D, JEMAL A, LOCKWOOD WW, SIEGEL R et al. Cancer statistics, 2012. CA Cancer J Clin 2012; 62: 10-29. https://doi.org/10.3322/caac.20138

[2] PREIS M, KORC M. Kinase signaling pathways as targets for intervention in pancreatic cancer. Cancer Biol Ther 2010; 9: 754-763. https://doi.org/10.4161/cbt.9.10.11534

[3] ADAMSKA A, DOMENICHINI A, FALASCA M. Pancreatic ductal adenocarcinoma: Current and evolving therapies. Int J Mol Sci 2017; 18: 1338. https://doi.org/10.3390/ ijms 18071338

[4] VINCENT A, HERMAN J, SCHULICK R, HRUBAN RH, GOGGINS M. Pancreatic cancer. Lancet 2011; 378: 607-620. https://doi.org/10.1016/S0140-6736(10)62307-0

[5] LIM JE, CHIEN MW, EARLE CC. Prognostic factors following curative resection for pancreatic adenocarcinoma: A population-based, linked database analysis of 396 patients. Ann Surg 2003; 237: 74-85. https://doi.org/10.1097/00000658200301000-00011

[6] SENER SF, FREMGEN A, MENCK HR, WINCHESTER DP. Pancreatic cancer: A report of treatment and survival trends for 100,313 patients diagnosed from 1985-1995, using the National Cancer Database. J Am Coll Surg 1999; 189: 1-7. https://doi.org/10.1016/s1072-7515(99)00075-7

[7] WAGNER M, REDAELLI C, LIETZ M, SEILER CA, FRIESS $\mathrm{H}$ et al. Curative resection is the single most important factor determining outcome in patients with pancreatic adenocarcinoma. Br J Surg 2004; 91: 586-594. https://doi.org/10.1002/ bjs. 4484

[8] REGINE WF, WINTER KA, ABRAMS RA, SAFRAN H, HOFFMAN JP et al. Fluorouracil vs gemcitabine chemotherapy before and after fluorouracil-based chemoradiation following resection of pancreatic adenocarcinoma: A randomized controlled trial. JAMA 2008; 299: 1019-1026. https:// doi.org/10.1001/jama.299.9.1019

[9] RAHIB L, SMITH BD, AIZENBERG R, ROSENZWEIG AB, FLESHMAN JM et al. Projecting cancer incidence and deaths to 2030: The unexpected burden of thyroid, liver, and pancreas cancers in the united states. Cancer Res 2014; 74: 2913 2921. https://doi.org/10.1158/0008-5472.CAN-14-0155

[10] ETHERIDGE A, LEE I, HOOD L, GALAS D, WANG K. Extracellular microRNA: A new source of biomarkers. Mutat Res 2011; 717: 85-90. https://doi.org/10.1016/j.mrfmmm.2011.03.004

[11] CHEUNG PY, SZAFRANSKA-SCHWARZBACH AE, SCHLAGETER AM, ANDRUSS BF, WEISS GJ. No miR quirk: dysregulation of microRNAs in pancreatic ductal adenocarcinoma. Microrna 2012; 1: 49-58. https://doi. org/10.2174/2211536611201010049

[12] SASSEN S, MISKA EA, CALDAS C. MicroRNA - Implications for cancer. Virchows Arch 2008; 452: 1-10. https://doi. org/10.1007/s00428-007-0532-2

[13] IORIO MV, CROCE CM. MicroRNA dysregulation in cancer: Diagnostics, monitoring and therapeutics. A comprehensive review. EMBO Mol Med 2012; 4: 143-159. https:// doi.org/10.1002/emmm.201100209 
[14] EUN JL, GUSEV Y, JIANG J, NUOVO GJ, LERNER MR et al. Expression profiling identifies microRNA signature in pancreatic cancer. Int J Cancer 2007; 120: 1046-1054. https:// doi.org/10.1002/ijc.22394

[15] SHENOUDA SK, ALAHARI SK. MicroRNA function in cancer: Oncogene or a tumor suppressor? Cancer Metastasis Rev 2009; 28: 369-378. https://doi.org/10.1007/s10555-0099188-5

[16] ZHANG B, PAN X, COBB GP, ANDERSON TA. MicroRNAs as oncogenes and tumor suppressors. Dev Biol 2007; 302: 1-12. https://doi.org/10.1016/j.ydbio.2006.08.028

[17] DU RIEU MC, TORRISANI J, SELVES J, AL SAATI T, SOUQUE A et al. MicroRNA-21 is induced early in pancreatic ductal adenocarcinoma precursor lesions. Clin Chem 2010; 56: 603-612. https://doi.org/10.1373/clinchem.2009.137364

[18] LE LARGE TYS, MEIJER LL, MATO PRADO M, KAZEMIER G, FRAMPTON AE et al. Circulating microRNAs as diagnostic biomarkers for pancreatic cancer. Expert Rev Mol Diagn 2016; 16: 715-717. https://doi.org/10.1080/14737159. 2016.1184573

[19] SZAFRANSKA AE, DOLESHAL M, EDMUNDS HS, GORDON S, LUTTGES J et al. Analysis of microRNAs in pancreatic fine-needle aspirates can classify benign and malignant tissues. Clin Chem 2008; 54: 1716-1724. https://doi. org/10.1373/clinchem.2008.109603

[20] LINK A, BECKER V, GOEL A, WEX T, MALFERTHEINER P. Feasibility of fecal microRNAs as novel biomarkers for pancreatic cancer. PLoS One 2012; 7: e42933. https://doi. org/10.1371/journal.pone.004293

[21] LIU A, XU X. MicroRNA isolation from formalin-fixed, paraffin-embedded tissues. Methods Mol Biol 2011; 724: 259-267. https://doi.org/10.1007/978-1-61779-055-3_16.

[22] NEGOI I, HOSTIUC S, SARTELLI M, NEGOI RI, BEURAN M. MicroRNA-21 as a prognostic biomarker in patients with pancreatic cancer - A systematic review and meta-analysis. Am J Surg 2018; 216: 1036. https://doi.org/10.1016/j.amjsurg.2018.07.049

[23] JAMIESON NB, MORRAN DC, MORTON JP, ALI A, DICKSON EJ et al. MicroRNA molecular profiles associated with diagnosis, clinicopathologic criteria, and overall survival in patients with resectable pancreatic ductal adenocarcinoma. Clin Cancer Res 2012; 18: 534-545. https://doi. org/10.1158/1078-0432.CCR-11-0679

[24] KONG X, DU Y, WANG G, GAO J, GONG Y et al. Detection of differentially expressed microRNAs in serum of pancreatic ductal adenocarcinoma patients: miR-196a could be a potential marker for poor prognosis. Dig Dis Sci 2011; 56: 602-609. https://doi.org/10.1007/s10620-010-1285-3

[25] PAPACONSTANTINOU IG, MANTA A, GAZOULI M, LYBEROPOULOU A, LYKOUDIS PM et al. Expression of microRNAs in patients with pancreatic cancer and its prognostic significance. Pancreas 2013; 42: 67-71. https://doi. org/10.1097/MPA.0b013e3182592ba7

[26] MIKAMORI M, YAMADA D, EGUCHI H, HASEGAWA S, KISHIMOTO T et al. MicroRNA-155 Controls Exosome Synthesis and Promotes Gemcitabine Resistance in Pancreatic Ductal Adenocarcinoma. Sci Rep 2017; 7: 42339. https:// doi.org/10.1038/srep42339
[27] GREITHER T, GROCHOLA LF, UDELNOW A, LAUTENSCHLÄGER C, WÜRL P et al. Elevated expression of microRNAs 155, 203, 210 and 222 in pancreatic tumors is associated with poorer survival. Int J Cancer 2010; 126: 73-80. https://doi.org/10.1002/ijc.24687

[28] YU Q, XU C, YUAN W, WANG C, ZHAO P et al. Evaluation of Plasma MicroRNAs as Diagnostic and Prognostic Biomarkers in Pancreatic Adenocarcinoma: miR-196a and miR210 Could Be Negative and Positive Prognostic Markers, Respectively. Biomed Res Int 2017; 2017: 6495867. https://doi. org/10.1155/2017/6495867

[29] DENG S, ZHU S, WANG B, LI X, LIU Y et al. Chronic pancreatitis and pancreatic cancer demonstrate active epithelial-mesenchymal transition profile, regulated by miR-217SIRT1 pathway. Cancer Lett 2014; 355: 184-191. https://doi. org/10.1016/j.canlet.2014.08.007

[30] BLOOMSTON M, FRANKEL WL, PETROCCA F, VOLINIA S, ALDER H et al. MicroRNA expression patterns to differentiate pancreatic adenocarcinoma from normal pancreas and chronic pancreatitis. JAMA 2007; 297: 1901-1908. https://doi.org/10.1001/jama.297.17.1901

[31] POPOV A, SZABO A, MANDYS V. Small nucleolar RNA U91 is a new internal control for accurate microRNAs quantification in pancreatic cancer. BMC Cancer 2015; 15: 774. https://doi.org/10.1186/s12885-015-1785-9

[32] PFAFFL MW. A new mathematical model for relative quantification in real-time RT-PCR. Nucleic Acids Res 2001; 29: e45. https://doi.org/10.1093/nar/29.9.e45

[33] HONG TH, PARK IY. MicroRNA expression profiling of diagnostic needle aspirates from surgical pancreatic cancer specimens. Ann Surg Treat Res 2014; 87: 290-297. https:// doi.org/10.4174/astr.2014.87.6.290

[34] WANG J, CHEN J, CHANG P, LEBLANC A, LI D et al. MicroRNAs in plasma of pancreatic ductal adenocarcinoma patients as novel blood-based biomarkers of disease. Cancer Prev Res (Phila) 2009; 2: 807-813. https://doi. org/10.1158/1940-6207.CAPR-09-0094

[35] ZHANG Y, LI M, WANG H, FISHER WE, LIN PH et al. Profiling of 95 MicroRNAs in pancreatic cancer cell lines and surgical specimens by real-time PCR analysis. World J Surg 2009; 33: 698-709. https://doi.org/10.1007/s00268-0089833-0

[36] SZAFRANSKA AE, DAVISON TS, JOHN J, CANNON T, SIPOS B et al. MicroRNA expression alterations are linked to tumorigenesis and non-neoplastic processes in pancreatic ductal adenocarcinoma. Oncogene 2007; 26: 4442-4452. https://doi.org/10.1038/sj.onc.1210228

[37] DU RIEU MC, TORRISANI J, SELVES J, AL SAATI T, SOUQUE A et al. MicroRNA-21 is induced early in pancreatic ductal adenocarcinoma precursor lesions. Clin Chem 2010; 56: 603-612. https://doi.org/10.1373/clinchem.2009.137364

[38] KENT OA, MULLENDORE M, WENTZEL EA, LÓPEZROMERO P, TAN AC et al. A resource for analysis of microRNA expression and function in pancreatic ductal adenocarcinoma cells. Cancer Biol Ther 2009; 8: 2013-2024. https://doi.org/10.4161/cbt.8.21.9685 
[39] YU S, LU Z, LIU C, MENG Y, MA Y et al. miRNA-96 suppresses KRAS and functions as a tumor suppressor gene in pancreatic cancer. Cancer Res 2010; 70: 6015-6025. https:// doi.org/10.1158/0008-5472.CAN-09-4531

[40] FENG J, YU J, PAN X, LI Z, CHEN Z et al. HERG1 functions as an oncogene in pancreatic cancer and is downregulated by miR-96. Oncotarget 2014; 5: 5832-5844. https://doi. org/10.18632/oncotarget.2200

[41] HANOUN N, DELPU Y, SURIAWINATA AA, BOURNET B, BUREAU C et al. The Silencing of MicroRNA 148a Production by DNA Hypermethylation Is an Early Event in Pancreatic Carcinogenesis. Clin Chem 2010; 56: 1107-1118. https://doi.org/10.1373/clinchem.2010.144709

[42] LUBEZKY N, LOEWENSTEIN S, BEN-HAIM M, BRAZOWSKI E, MARMOR S et al. MicroRNA expression signatures in intraductal papillary mucinous neoplasm of the pancreas. Surgery 2013; 153: 663-672. https://doi.org/10.1016/j. surg.2012.11.016.

[43] WANG J, RAIMONDO M, GUHA S, CHEN J, DIAO L et al. Circulating microRNAs in Pancreatic Juice as Candidate Biomarkers of Pancreatic Cancer. J Cancer 2014; 5: 696-705. https://doi.org/10.7150/jca.10094

[44] LUTHRA R, SINGH RR, LUTHRA MG, LI YX, HANNAH C et al. MicroRNA-196a targets annexin A1: a microRNA-mediated mechanism of annexin A1 downregulation in cancers. Oncogene 2008; 27: 6667-6678. https://doi.org/10.1038/ onc. 2008.256

[45] LEE YS, KIM H, KIM HW, LEE J-C, PAIK K-H, et al. High Expression of MicroRNA-196a Indicates Poor Prognosis in Resected Pancreatic Neuroendocrine Tumor. Medicine (Baltimore) 2015; 94: e2224. https://doi.org/10.1097/ MD.0000000000002224

[46] XU YF, HANNAFON BN, ZHAO YD, POSTIER RG, DING WQ. Plasma exosome miR-196a and miR-1246 are potential indicators of localized pancreatic cancer. Oncotarget 2017; 8: 77028-77040. https://doi.org/10.18632/oncotarget.20332

[47] MA MZ, KONG X, WENG MZ, CHENG K, GONG W et al. Candidate microRNA biomarkers of pancreatic ductal adenocarcinoma: meta-analysis, experimental validation and clinical significance. J Exp Clin Cancer Res 2013; 32: 71. https://doi.org/10.1186/1756-9966-32-71

[48] SCHULTZ NA, WERNER J, WILLENBROCK H, ROSLIND A, GIESE $\mathrm{N}$ et al. MicroRNA expression profiles associated with pancreatic adenocarcinoma and ampullary adenocarcinoma. Mod Pathol 2012; 25: 1609-1622. https://doi. org/10.1038/modpathol.2012.122

[49] QI L, BART J, TAN LP, PLATTEEL I, VAN DER SLUIS T et al. Expression of miR-21 and its targets (PTEN, PDCD4, TM1) in flat epithelial atypia of the breast in relation to ductal carcinoma in situ and invasive carcinoma. BMC Cancer 2009; 9: 163. https://doi.org/10.1186/1471-2407-9-163

[50] HO AS, HUANG X, CAO H, CHRISTMAN-SKIELLER C, BENNEWITH K et al. Circulating miR-210 as a Novel Hypoxia Marker in Pancreatic Cancer. Transl Oncol 2010; 3: 109-113. https://doi.org/10.1593/tlo.09256

[51] HUANG X, LE Q-T, GIACCIA AJ. MiR-210--micromanager of the hypoxia pathway. Trends Mol Med 2010; 16: 230-237. https://doi.org/10.1016/j.molmed.2010.03.004
[52] ZHAO WG, YU SN, LU ZH, MA YH, GU YM et al. The miR217 microRNA functions as a potential tumor suppressor in pancreatic ductal adenocarcinoma by targeting KRAS. Carcinogenesis 2010; 31: 1726-1733. https://doi.org/10.1093/ carcin/bgq160

[53] FENG H, WANG Y, SU J, LIANG H, ZHANG CY et al. MicroRNA-148a Suppresses the Proliferation and Migration of Pancreatic Cancer Cells by Down-regulating ErbB3. Pancreas 2016; 45: 1263-1271. https://doi.org/10.1097/ MPA.0000000000000677

[54] CHANG X, YU C, LI J, YU S, CHEN J. hsa-miR-96 and hsa-miR-217 Expression Down-Regulates with Increasing Dysplasia in Pancreatic Intraepithelial Neoplasias and Intraductal Papillary Mucinous Neoplasms. Int J Med Sci 2017; 14: 412-418. https://doi.org/10.7150/ijms.18641

[55] HABBE N, KOORSTRA JBM, MENDELL JT, OFFERHAUS GJ, JI KR et al. MicroRNA miR-155 is a biomarker of early pancreatic neoplasia. Cancer Biol Ther 2009; 8: 340-346. https://doi.org/10.4161/cbt.8.4.7338

[56] FRAMPTON AE, CASTELLANO L, COLOMBO T, GIOVANNETTI E, KRELL J et al. MicroRNAs cooperatively inhibit a network of tumor suppressor genes to promote pancreatic tumor growth and progression. Gastroenterology 2014; 146: 268-77.e18. https://doi.org/10.1053/j.gastro.2013.10.010

[57] GIOVANNETTI E, FUNEL N, PETERS GJ, DEL CHIARO M, EROZENCI LA et al. MicroRNA-21 in pancreatic cancer: correlation with clinical outcome and pharmacologic aspects underlying its role in the modulation of gemcitabine activity. Cancer Res 2010; 70: 4528-4538. https://doi. org/10.1158/0008-5472.CAN-09-4467

[58] DILLHOFF $M$, LIU J, FRANKEL W, CROCE C, BLOOMSTON M. MicroRNA-21 is overexpressed in pancreatic cancer and a potential predictor of survival. J Gastrointest Surg 2008; 12: 2171-2176. https://doi.org/10.1007/ s11605-008-0584-x

[59] SCHULTZ NA, ANDERSEN KK, ROSLIND A, WILLENBROCK H, WØJDEMANN M et al. Prognostic MicroRNAs in Cancer Tissue from Patients Operated for Pancreatic Cancer-Five MicroRNAs in a Prognostic Index. World J Surg 2012; 36: 2699-2707. https://doi.org/10.1007/s00268-012-1705-y

[60] SUH N. MicroRNA controls of cellular senescence. BMB Rep 2018; 51: 493-499. https://doi.org/10.5483/BMBRep.2018.51.10.209

[61] BALLEHANINNA UK, CHAMBERLAIN RS. The clinical utility of serum CA 19-9 in the diagnosis, prognosis and management of pancreatic adenocarcinoma: An evidence based appraisal. J Gastrointest Oncol 2012; 3: 105-119. https://doi.org/10.3978/j.issn.2078-6891.2011.021

[62] WALD P, LIU XS, PETTIT C, DILLHOFF M, MANILCHUK A et al. Prognostic value of microRNA expression levels in pancreatic adenocarcinoma: a review of the literature. Oncotarget 2017; 8: 73345-73361. https://doi.org/10.18632/oncotarget. 20277

[63] HU G, TAO F, WANG W, JI K. Prognostic value of microRNA-21 in pancreatic ductal adenocarcinoma: a meta-analysis. World J Surg Oncol 2016; 14: 82. https://doi.org/10.1186/ s12957-016-0842-4 
[64] ZHU W, XU B. MicroRNA-21 Identified as Predictor of Cancer Outcome: A Meta-Analysis. PLoS One 2014; 9: e103373. https://doi.org/10.1371/journal.pone.0103373

[65] FRAMPTON AE, KRELL J, JAMIESON NB, GALL TMH, GIOVANNETTI E et al. microRNAs with prognostic significance in pancreatic ductal adenocarcinoma: A meta-analysis. Eur J Cancer 2015; 51: 1389-1404. https://doi.org/10.1016/j. ejca.2015.04.006

[66] KARASEK P, GABLO N, HLAVSA J, KISS I, VYCHYTILOVA-FALTEJSKOVA P et al. Pre-operative Plasma miR-21-5p Is a Sensitive Biomarker and Independent Prognostic Factor in Patients with Pancreatic Ductal Adenocarcinoma Undergoing Surgical Resection. Cancer Genomics Proteomics 2018; 15: 321-327. https://doi.org/10.21873/cgp.20090

[67] CALATAYUD D, DEHLENDORFF C, BOISEN MK, HASSELBY JP, SCHULTZ NA et al. Tissue MicroRNA profiles as diagnostic and prognostic biomarkers in patients with resectable pancreatic ductal adenocarcinoma and periampullary cancers. Biomark Res 2017; 5: 8. https://doi.org/10.1186/ s40364-017-0087-6

[68] KHAN K, CUNNINGHAM D, PECKITT C, BARTON S, TAIT D et al. miR-21 expression and clinical outcome in locally advanced pancreatic cancer: exploratory analysis of the pancreatic cancer Erbitux, radiotherapy and UFT (PERU) trial. Oncotarget 2016; 7: 12672-12681. https://doi. org/10.18632/oncotarget.7208

[69] DONAHUE TR, NGUYEN AH, MOUGHAN J, LI L, TATISHCHEV $S$ et al. Stromal MicroRNA-21 Levels Predict Response to 5-Fluorouracil in Patients with Pancreatic Cancer. J Surg Oncol 2014; 110: 952-959. https://doi. org/10.1002/jso. 23750

[70] KADERA BE, LI L, TOSTE PA, WU N, ADAMS C et al. MicroRNA-21 in pancreatic ductal adenocarcinoma tumorassociated fibroblasts promotes metastasis. PLoS One 2013; 8: e71978. https://doi.org/10.1371/journal.pone.0071978

[71] LI C, DU X, TAI S, ZHONG X, WANG Z et al. GPC1 Regulated by miR-96-5p, Rather than miR-182-5p, in Inhibition of Pancreatic Carcinoma Cell Proliferation. Int J Mol Sci 2014; 15: 6314-6327. https://doi.org/10.3390/ijms15046314

[72] VYCHYTILOVA-FALTEJSKOVA P, KISS I, KLUSOVA S, HLAVSA J, PROCHAZKA V et al. MiR-21, miR-34a, miR198 and miR-217 as diagnostic and prognostic biomarkers for chronic pancreatitis and pancreatic ductal adenocarcinoma. Diagn Pathol 2015; 10: 38. https://doi.org/10.1186/ s13000-015-0272-6

[73] ZHOU X, HUANG Z, XU L, ZHU M, ZHANG L et al. A panel of 13-miRNA signature as a potential biomarker for predicting survival in pancreatic cancer. Oncotarget 2016; 7: 69616-69624. https://doi.org/10.18632/oncotarget.11903
[74] LIANG L, WEI DM, LI JJ, LUO DZ, CHEN G et al. Prognostic microRNAs and their potential molecular mechanism in pancreatic cancer: A study based on The Cancer Genome Atlas and bioinformatics investigation. Mol Med Rep 2018; 17: 939-951. https://doi.org/10.3892/mmr.2017.7945

[75] SHI XH, LI X, ZHANG H, HE RZ, ZHAO Y, ZHOU M et al. A Five-microRNA Signature for Survival Prognosis in Pancreatic Adenocarcinoma based on TCGA Data. Sci Rep 2018; 8: 7638. https://doi.org/10.1038/s41598-018-22493-5

[76] YOU L, WANG J, ZHANG F, ZHANG J, TAO H et al. Potential four miRNA signature associated with $\mathrm{T}$ stage and prognosis of patients with pancreatic ductal adenocarcinoma identified by co expression analysis. Mol Med Rep 2019; 19: 441-451. https://doi.org/10.3892/mmr.2018.9663

[77] ANAYA J. OncoLnc: linking TCGA survival data to mRNAs, miRNAs, and lncRNAs. PeerJ Computer Science 2016; 2: e67. https://doi.org/10.7717/peerj-cs.67

[78] MAXWELL GL, SHOJI Y, DARCY K, LITZI T, BERCHUCK A et al. MicroRNAs in endometrial cancers from black and white patients. Am J Obstet Gynecol 2015; 212: 191.e1-10. https://doi.org/10.1016/j.ajog.2014.08.028

[79] BOISEN MK, DEHLENDORFF C, LINNEMANN D, SCHULTZ NA, JENSEN BV, HØGDALL EV and JOHANSEN JS. MicroRNA Expression in Formalin-fixed Paraffinembedded Cancer Tissue: Identifying Reference MicroRNAs and Variability. BMC Cancer 2015; 15: 1024. https://doi. org/10.1186/s12885-015-2030-2.

[80] VOJTECHOVA Z, ZAVADIL J, KLOZAR J, GREGA M, TACHEZY R. Comparison of the miRNA expression profiles in fresh frozen and formalin-fixed paraffin-embedded tonsillar tumors. PLoS One 2017; 12: e0179645. https://doi. org/10.1371/journal.pone.0179645

[81] LE LARGE TY, MEIJER LL, PRADO MM, KAZEMIER G, FRAMPTON AE et al. Circulating microRNAs as diagnostic biomarkers for pancreatic cancer. Expert Rev Mol Diagn 2015; 15: 1525-1529. https://doi.org/10.1586/14737159.2015 .1112273

[82] CARLSSON J, DAVIDSSON S, FRIDFELDT J, GIUNCHI F, FIANO V et al. Quantity and quality of nucleic acids extracted from archival formalin fixed paraffin embedded prostate biopsies. BMC Med Res Methodol 2018; 18: 161. https://doi. org/10.1186/s12874-018-0628-1

[83] SZAFRANSKA AE, DAVISON TS, SHINGARA J, DOLESHAL M, RIGGENBACH JA et al. Accurate molecular characterization of formalin-fixed, paraffin-embedded tissues by microRNA expression profiling. J Mol Diagn 2008; 10: 415-423. https://doi.org/10.2353/jmoldx.2008.080018

[84] MESTDAGH P, HARTMANN N, BAERISWYL L, ANDREASEN D, BERNARD $N$ et al. Evaluation of quantitative miRNAexpression platforms in the microRNA quality control (miRQC) study. Nat Methods 2014; 11: 809-815. https:// doi.org/10.1038/nmeth.3014 